\title{
POCKET BOOK KEANEKARAGAMAN MANGROVE DI KAWASAN TELUK SEPANG SEBAGAI MEDIA BELAJAR TAKSONOMI TUMBUHAN II
}

\author{
Selvina Agnestia ${ }^{1 *}$, Kasrina ${ }^{1}$, Ariefa P. Yani ${ }^{1}$ \\ ${ }^{1}$ Program Studi Pendidikan Biologi, Fakultas Keguruan dan Ilmu Pendidikan, Universitas Bengkulu \\ Email: selvinaagnestia@gmail.com
}

\begin{abstract}
Abstrak
Penelitian ini bertujuan untuk mengetahui kelayakan buku saku (pocket book) yang dikembangkan berdasarkan hasil dari identifikasi spesies mangrove dalam matakuliah Taksonomi Tumbuhan II. Pada penelitian ini menggunakan metode Penelitian dan Pengembangan (Research and Development). Teknik pengumpulan data pada penelitian ini adalah angket (kuisioner). Instrumen yang digunakan adalah lembar angket untuk dua orang validator (satu validator media ajar dan satu validator materi ajar), dan uji keterbacaan buku saku dilakukan kepada mahasiswa Pendidikan Biologi UNIB. Berdasarkan hasil uji validasi buku saku yang dilakukan oleh validator media ajar dengan presentase $81,25 \%$ dan uji validasi yang dilakukan oleh validator materi ajar dengan presentase $93,75 \%$. Kedua skor tersebut mendapatkan presentase $87,5 \%$ (Sangat Valid). Sementara dari hasil uji keterbacaan terhadap mahasiswa diperoleh persentase sebesar $86,3 \%$ (Sangat Valid). Berdasarkan hasil uji validitas dan keterbacaan tersebut, buku saku yang dikembangkan, layak digunakan sebagai media ajar dalam Mata kuliah Taksonomi Tumbuhan II. Buku saku dapat memudahkan dalam penggunaannya yang mudah dibawa serta dengan isi buku saku yang lengkap beserta gambar yang jelas.
\end{abstract}

Kata Kunci : Buku saku, Mangrove, Teluk Sepang

\begin{abstract}
This study aims to determine the feasibility of pocket books developed based on the results of identification of mangrove species in the course of the Plant Taxonomy II. Data collection techniques in this study were questionnaires (questionnaire). The instrument used was a question naire sheet for two validators (one teaching media validator and one teaching material validator), and a pocket book read ability test was conducted for UNIB Biology Education students. Based on the results of the pocket book validation test conducted by the teaching media validator score of $26 / 32$ or $81.25 \%$ and the validation test conducted by the validator of the teaching material the score was $30 / 32$ or $93.75 \%$. Both of these scores received a percentage of $87.5 \%$ with the category "Very Valid". While the results of there adability test for students found a percentageof $86.3 \%$ with the category "Very Valid". Based on the results of the validity and readability test, the developed pocket book is suitable to be used as a medium for teaching Plant Taxonomy II.
\end{abstract}

Keywords: Pocketbook, Mangrove, Teluk Sepang

\section{PENDAHULUAN}

$\begin{array}{ll}\text { Taksonomi tumbuhan merupakan } & \text { acuan sebagai sistematik tumbuhan } \\ \text { cabang ilmu biologi yang mencakup } & \text { (Lawrence, 1951). Mata kuliah taksonomi } \\ \text { mengenai identifikasi, tatanama, serta } & \text { tumbuhan menjadi matakuliah wajib yang } \\ \text { klasifikasi objek yang biasanya terbatas } & \text { dipelajari pada Program Studi Pendidikan } \\ \text { pada objek biologi, dan yang terbatas hanya } & \text { Biologi Universitas Bengkulu. Matakuliah ini } \\ \text { pada tumbuhan saja, serta sering menjadi } & \text { dibagi menjadi 2, yaitu Taksonomi }\end{array}$


Tumbuhan I (TT I) dengan mempelajari mengenai tumbuhan tingkat rendah (belum berpembuluh), dan Taksonomi Tumbuhan II (TT II) yang mempelajari mengenai tumbuhan tingkat tinggi (sudah berpembuluh).

Dalam mata kuliah Taksonomi Tumbuhan II terdapat materi dengan Kompetensi Dasar (KD) memahami prinsip identifikasi dan menerapkan kunci identifikasi dengan metode pengidentifikasian tumbuhan. Pada proses pengidentifikasian tumbuhan ini, mahasiswa melakukan praktikum atau mengeksplorasi tumbuhan secara langsung ke lapangan, namun belum ada media ajar yang praktis dan efisien sehingga memudahkan mahasiswa sebagai pendamping pembelajaran ketika di lapangan. Media ajar yang praktis dan efisien dapat berupa buku saku (pocketbook).

Buku saku (Pocket book) memiliki kriteria utama yaitu ringan dan dapat disimpan di saku (Setiawan, 2013). Buku saku juga dapat diartikan sebagai buku yang berisi mengenai berbagai macam informasi dengan memiliki ukuran yang kecil yang dapat dimasukkan kedalam saku sehingga memudahkan seseorang untuk membawanya dan dapat digunakan kemana dan dimana saja (Poerwadarminta, 2006).

Penggunaan buku saku ini sangat bermanfaat bagi penggunanya karena selain efisien dalam waktu dan tenaga serta sistem materi yang disampaikan didalamnya dapat disesuaikan, penggunaan buku saku juga dapat lebih jelas dan lebih menyenangkan pembacanya. Buku saku dapat lebih menarik pembaca karena desain dari buku saku cenderung menarik dan dicetak dengan "fullcolour" (Sulistyani dkk, 2013). Didalam buku saku dicetak menarik agar dapat menarik perhatian seperti penggunaan warna dan gambar. Menurut Ami (2012) warna merupakan bentuk komunikasi non-verbal yang membuat komunikasi atau penyampaian pesan yang lebih bermakna. Buku saku juga memuat informasi yang lebih fokus didalam nya (Susilana dan Cepi, 2008).

Adanya buku saku tentunya sangat membantu dalam proses identifikasi ketika di lapangan. Media pembelajaran seperti buku saku ini berfungsi untuk mendukung serta memudahkan dalam penyampaian materi sesuai konteks. Akan tetapi tidak hanya terbatas pada buku saku saja, tetapi juga dapat dibuat dengan memperoleh data-data yang berasal dari lingkungan. Berdasarkan Permenristekdikti No. 44 Tahun 2015, yang menuturkan bahwa pembelajaran adalah proses interaksi mahasiswa dengan dosen dan sumber belajar pada suatu lingkungan belajar. Bentuk-bentuk pembelajaran juga dapat dengan pengajaran tambahan yang memadukan antara lingkungan, budaya, dan konsep (Zukmadini, 2018).

Pemanfaatan lingkungan sebagai sumber belajar akan dapat memberikan pengalaman belajar yang lebih menarik dan bermakna. Berdasarkan hal tersebut, maka peneliti memilih lokasi penelitian yaitu Teluk Sepang Kota Bengkulu, karena Teluk Sepang merupakan daerah yang memiliki keanekaragaman tumbuhan yang dapat dijadikan sumber belajar salah satunya tumbuhan mangrove.

Hutan mangrove merupakan hutan yang tumbuh dan hidup di daerah pantai yang memiliki sistem air yang cenderung tenang dan berada di tempat yang terlindungi dari hempasan air ombak serta eksistensi dari hutan mangrove ini bergantung pada aliran air sungai dan aliran 
air laut (Pramudji, 2000). Berdasarkan Peraturan Menteri Kehutanan No.P.03/MENHUT-V/2004, hutan mangrove adalah hutan yang tumbuh pada tanah alluvial di daerah pantai dan sekitar muara sungai yang di pengaruhi oleh pasang surut laut dan dicirikan oleh jenis-jenis pohon seperti Avecennia, Sonneratia, Rhizophora, Bruguiera dan lain - lain. Mangrove yang tersebar di lapangan dapat dijadikan sumber belajar dalam bentuk buku saku mengenai mangrove pada mata kuliah Taksonomi Tumbuhan II, hal ini karena penggunaan buku saku mengenai identifikasi mangrove ini berisi materi yang mudah dipahami dan buku saku lebih praktis digunakan ketika di lapangan.

Adapun hasil penelitian ini berupa buku saku yang diharapkan mampu mempermudah mahasiswa dalam matakuliah Taksonomi Tumbuhan II mengenai keanekaragaman tumbuhan mangrove. Dimana buku saku ini berisi mengenai informasi yang lengkap dengan keterangan gambar yang jelas, dan buku saku didesain sedemikian rupa untuk memuat hasil identifikasi mangrove di Teluk Sepang Kota Bengkulu. Berdasarkan latar belakang tersebut, maka penulis tertarik melakukan penelitian dengan judul "Pocket Book Keanekaragaman Mangrove Di Kawasan Teluk Sepang Sebagai Media Belajar Taksonomi Tumbuhan II", dengan Kompetensi Dasar (KD) pada materi ini adalah Memahami sumber bukti taksonomi atau ciri taksonomi.

\section{METODE}

Penelitian ini menggunakan metode Penelitian dan Pengembangan (Researchand Development) yang dikembangkan oleh Sugiyono (2012), yang terdiri dari 10 tahap yaitu: (1) potensi dan masalah; (2) pengumpulan data; (3) desain produk; (4) validasi desain; (5) revisi desain; (6) uji coba produk; (7) revisi produk; (8) uji pemakaian; (9) revisi produk; dan (10) produksi massal. Namun pada penelitian ini karena keterbatasan waktu hanya dilakukan hingga tahap ke-7.

Penelitian ini telah dilaksanakan pada bulan Desember 2018 s/d April 2019. Subjek penelitian ini adalah Mahasiswa Pendidikan Biologi yang telah mengikuti matakuliah Taksonomi Tumbuhan II. Pada penelitian ini terdapat 2 dosen sebagai validator. Satu orang dosen sebagai validator media ajar dan satu dosen sebagai validator materi ajar. Uji keterbacaan dilakukan terhadap 28 orang mahasiswa Pendidikan Biologi. Teknik pengumpulan data dalam penelitian ini menggunakan lembar angket (kuesioner) yang terdiri atas angket uji kelayakan untuk validator (media ajar \& materi ajar), dan angket uji keterbacaan buku saku untuk mahasiswa. Data uji validasi dan uji keterbacaan yang terkumpul dianalisis secara deskriptif kuantitatif. Angka hasil uji yang diperoleh diubah ke dalam persentase kelayakan dengan rumus :

$$
\frac{\text { Jumlah hasil pengumpulan data }}{\text { Skor maksimal }}
$$

(Riduwan, 2013).

Data validasi dari validator dianalisis secara kuantitatif untuk memberikan gambaran tentang buku saku dalam bentuk skor atau nilai. Dalam pemberian skor digunakan acuan berdasarkan skala likert yang dapat dilihat pada Tabel 1. 
Tabel 1. Skala Likert

\begin{tabular}{cc}
\hline Penilaian & Nilai Skala \\
\hline Kurang Baik & 1 \\
Cukup Baik & 2 \\
Baik & 3 \\
Sangat Baik & 4 \\
\hline
\end{tabular}

(Riduwan, 2013).

Hasil skor yang telah didapatkan berdasarkan analisis data lembar angket yang telah diisi kemudian diinterpretasikan berdasarkan criteria penilaian hasil validasi yang dapat dilihat pada Tabel 2 .

Tabel 2. Kriteria Penilaian Hasil Validasi

\begin{tabular}{|c|c|c|}
\hline $\begin{array}{l}\text { Skala } \\
\text { Nilai }\end{array}$ & Keterangan & Keputusan Uji \\
\hline $86-100$ & Sangat Valid & $\begin{array}{l}\text { Sangat layak dan } \\
\text { tidak revisi jika } \\
\text { mencapai } 100 \%\end{array}$ \\
\hline $71-85$ & Valid & $\begin{array}{c}\text { Layak namun tetap } \\
\text { dilakukan revisi } \\
\text { kecil }\end{array}$ \\
\hline $56-70$ & Cukup Valid & $\begin{array}{l}\text { Cukup layak dan } \\
\text { perlu revisi besar }\end{array}$ \\
\hline $41-55$ & Kurang Valid & $\begin{array}{l}\text { Kurang layak dan } \\
\text { perlu revisi besar }\end{array}$ \\
\hline $25-40$ & $\begin{array}{c}\text { Sangat kurang } \\
\text { valid }\end{array}$ & $\begin{array}{l}\text { Tidak layak dan } \\
\text { perlu revisi besar }\end{array}$ \\
\hline
\end{tabular}

\section{HASIL DAN PEMBAHASAN}

Pengembangan buku saku berdasarkan hasil eksplorasi tumbuhan mangrove di Teluk Sepang. Buku saku ini merupakan suplemen media ajar Taksonomi Tumbuhan II dengan materi identifikasi tumbuhan.

Berdasarkan penelitian yang telah dilakukan data hasil validasi buku saku oleh validator dapat dilihat pada Tabel 3.
Tabel 3. Hasil Analisis Uji Validasi

\begin{tabular}{ccccc}
\hline No & Validator & $\begin{array}{c}\text { Skor } \\
\text { Akhir }\end{array}$ & Persentase & Kriteria \\
\hline 1 & Media & 26 & $81,25 \%$ & Valid \\
2 & Materi & 30 & $93,75 \%$ & $\begin{array}{c}\text { Sangat } \\
\text { Valid }\end{array}$ \\
& Rerata & & $87,5 \%$ & $\begin{array}{c}\text { Sangat } \\
\text { Valid }\end{array}$ \\
\hline
\end{tabular}

Secara keseluruhan berdasarkan uji validitas oleh kedua validator buku saku termasuk kriteria sangat valid dengan persentase rata-rata dari hasil angket keduavalidator sebesar $87,5 \%$. Namun terdapat beberapa saran dari validator terhadap buku saku, antara lain :

1) Perbaiki latar belakang atau background di setiap lembar buku saku agar buku saku lebih menarik pengguna untuk membacanya

2) Penambahan identitas penulis/biografi penulis pada buku saku.

3) Perbaiki komponen materi pada buku saku, yaitu mengenai zonasi mangrove yang termasuk dalam karakteristik tumbuhan mangrove

4) Perbaiki komponen gambar dalam buku saku untuk dilengkapi dan lebih diperjelas.

Setelah didapatkan hasil uji validasi oleh kedua validator, maka buku saku dilakukan uji keterbacaan terhadap mahasiswa Pendidikan Biologi, yang dilihat pada Gambar 4 .

Tabel 4. Hasil Analisis Uji Keterbacaan

\begin{tabular}{ccccc}
\hline No & Jumlah & Skor & Persentase & Kriteria \\
& Mahasiswa & Akhir & & \\
\hline 1 & 28 orang & 1161 & $86,3 \%$ & Sangat \\
& & & & Valid \\
\hline
\end{tabular}


Berdasarkan Tabel 4 diatas, bahwa hasil uji keterbacaan buku saku keanekaragaman mangrove di Teluk Sepang kepada mahasiswa pendidikan biologi adalah "sangat valid". Artinya buku saku dapat digunakan dalam proses perkuliahan dengan matakuliah Taksonomi Tumbuhan I . Hasil analisis dari kedua validator yaitu media ajar dan materi ajar, maka produk yang telah dibuat yaitu buku saku keanekaragaman jenis mangrove di Teluk Sepang telah layak untuk dilakukan uji keterbacaan kepada mahasiswa Pendidikan Biologi yang telah mengikuti mata kuliah Taksonomi Tumbuhan II. Uji keterbacaan terhadap 28 responden. Penilaian dilakukan berdasarkan 12 indikator. Pada setiap indikator memiliki nilai 1-4. Nilai 4 merupakan nilai tertinggi, sedangkan nilai 1 merupakan nilai terendah. Dari semua hasil analisis uji keterbacaan, diperoleh hasil akhir dengan presentase mencapai $86 \%$ dengan kriteria sangat valid. Dengan hasil sangat valid tersebut, maka buku saku keanekaragaman jenis mangrove di Teluk Sepang yang telah dibuat dapat digunakan sebagai media belajar dalam mata kuliah Taksonomi Tumbuhan II. Hal ini sesuai dengan (Akbar, 2013) yang menyatakan bahwa media pembelajaran dapat dikatakan layak bila rata-rata persentase dari angket validasi ahli media, ahli materi dan respon siswa diatas $70 \%$. Hasil ini juga sesuai dengan penelitian Windayani (2017) bahwa presentasi keidealan mencapai $89 \%$ dengan kategori sangat valid.

Kritik serta saran yang didapatkan dari mahasiswa Pendidikan Biologi sebagai responden bermacam-macam, terdapat kritik untuk penambahan gambar dan warna - warna, agar buku saku terlihat lebih menarik. Serta mahasiswa tertarik dengan materi mangrove karena buku saku yang dibuat berdasarkan lingkungan sekitar, dan terdapat beberapa kalimat yang tidak berspasi atau berjarak. Dari kritik dan saran yang diberikan, dapat dikatakan bahwa mahasiswa menyukai bacaan yang menarik dengan memiliki banyak gambar untuk menambah daya tarik untuk membaca. Hal ini sesuai dengan (Suharnan 2005) yang mengatakan bahwa didalam buku yang terdapat gambar didalamnya dapat lebih menarik perhatian untuk dibaca karena pembaca dapat dibuat berimajinasi dengan gambar - gambar yang tersedia tersebut. berimajinasi dapat membantu seseorang dalam daya ingatnya. Merujuk pada Alif, Dewi dan Kasrina (2018), buku saku yang disusun merupakan buku saku berpotensi local karena mudah ditemukan di lingkungan sekitar.

\section{PENUTUP}

Simpulan

Buku saku keanekaragaman jenis mangrove di kawasan Teluk Sepang Kota Bengkulu yang telah didesain berdasarkan hasil validasi buku saku dinyatakan termasuk kedalam kriteria sangat valid dengan persentase rata - rata 87,5 \% serta berdasarkan hasil uji keterbacaan oleh 28 orang mahasiswa Pendidikan Biologi UNIB dinyatakan termasuk kedalam kriteria sangat valid dengan persentase $86,3 \%$. Sehingga dapat di hasilkan bahwa buku saku ini layak untuk digunakan.

\section{Saran}

Diharapkan untuk lebih teliti dalam mendesain buku saku. Buku saku agar 
didesain sebagaimana mestinya agar memuat isi yang lengkap dan menarik untuk dibaca.

\section{DAFTAR PUSTAKA}

Akbar, S. 2013. Instrumen Perangkat Pembelajaran. Bandung: Remaja Rosdakarya.

Ami, M. S., Susanti, E. \& Raharjo. 2012. Pengembangan Buku saku Materi Sistem Ekskresi Manusia di SMA / MA. Bioedu Unesa. Surabaya : Universitas Negeri Surabaya (https://jurnalmahasiswaunesa.ac.id /index.php/bioedu/article/viewfile/4 39/342 diakes pada tanggal 29 Maret 2019).

KEMENRISTEKDIKTI. 2015. Peraturan Kementerian Riset, Teknologi, Dan Pendidikan Tinggi Republik Indonesia Nomor 44 Tahun 2015 tentang Standar Nasional Pendidikan Tinggi. Jakarta : Kementrian Riset, Teknologi, Dan Pendidikan Tinggi.

Lawrence, G.H.M. 1951. Taxonomy of Vascular Plants. New York : The Macmillan Company.

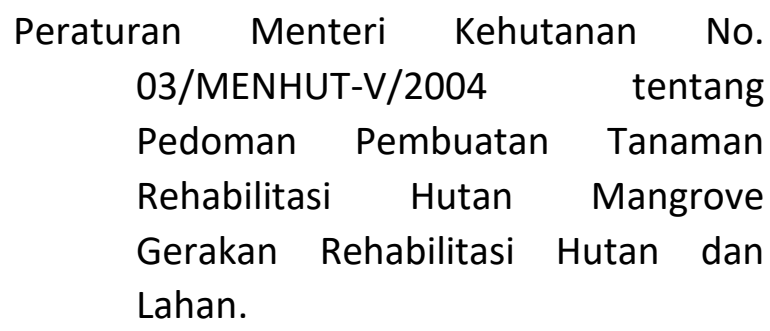

Poerwadarminta, W.J.S. 2006. Kamus Umum Bahasa Indonesia Edisi Ketiga. Jakarta : Balai Pustaka.

Pramudji. 2000. Hutan Mangrove di Indonesia : Peranan Permasalahan dan Pengelolaannya.Jurnal Biologi Puslitbang Oseanologi LIPI) http://oseanografi.lipi.go.id/dokume n/oseana_xxv(1)13-20.pdf diakses pada tanggal 05 September 2018).

Riduwan. 2013. Skala Pengukuran Variabelvariabel Penelitian. Bandung : ALFABETA.

Setiawan, Andi. 2013. Penerapan Buku Saku Mastercam Untuk Meningkatkan Keaktifan dan Kompetensi Siswa. Yogyakarta : Universitas Yogyakarta.

Sugiyono. 2012. Metode Penelitian Pendidikan Pendekatan Kuantitatif, Kualitatif dan R\&D. Bandung : ALFABETA.

Suharnan. 2005. Psikologi Kognitif. Surabaya : Srikandi.

Sulistyani, N.H.D., Jamzuri dan D.T Rahardjo. 2013. Perbedaan Hasil Belajar Siswa Antara Menggunakan Media PocketBook dan Tanpa Pocket Book Pada Materi Kinematika Gerak Melingkar Kelas X. Jurnal Materi dan Pembelajaran Fisika(2013) 1 (1) : 164 I http://jurnal.fkip.uns.ac.id/index.ph p/pfisika/article/view/1784/1277 
diakses pada tanggal 07 November 2018).

Susilana, Hadi dan Cepi Riyana. 2008. Media Pembelajaran Hakekat Pengembangan dan Pemanfaatan dan Penilaian. Bandung : Wacana Prima.

Windayani., Kasrina., Irwandi, A. 2017. Pengembangan Buku Saku Berdasarkan Hasil Eksplorasi TanamanObatSuku Rejang di Desa Pulo Geto. Diklabio :Jurnal Pendidikan dan Pembelajaran Biologi. (Online). (https://ejournal.unib.ac.id/index.ph p/jppb/article/view/5142/2701).

Diakses pada tanggal 26 Juli 2019

Zukmadini, A., Dewi, J., \& Kasrina. 2018. Developing Antimicrobial Plants Pocketbook ased on Lokal Wisdom of Muko-Muko and Serawai Ethnich. Jurnal Pendidikan Biologi Indonesia. 4(2): $\quad$ 95-104 (Online). (http://ejournal.umm.ac.id/index.ph p/jpbi/articel/download/5436/5518, diakses 24 Juli 2019. 